\title{
Erratum to: Response of Non-Local and Phase-Lags due to Ramp-Type Loading in Modified Couple Stress Thermoelastic with Mass Diffusion
}

\author{
Rajneesh Kumar ${ }^{a}$, Sachin Kaushal ${ }^{b, *}$, and Vikram ${ }^{b}$ \\ ${ }^{a}$ Department of Mathematics, Kurukshetra University Kurukshetra, India \\ ${ }^{b}$ Department of Mathematics, School of Chemical Engineering and Physical Sciences, \\ Lovely Professional University-Phagwara, India \\ *e-mail:sachin_kuk@yahoo.co.in \\ Received September 16, 2020; revised September 16, 2020; accepted September 16, 2020
}

DOI: $10.3103 / \mathrm{S} 0025654421060066$

Figures $1-10$ in the paper should be replaced as follows:

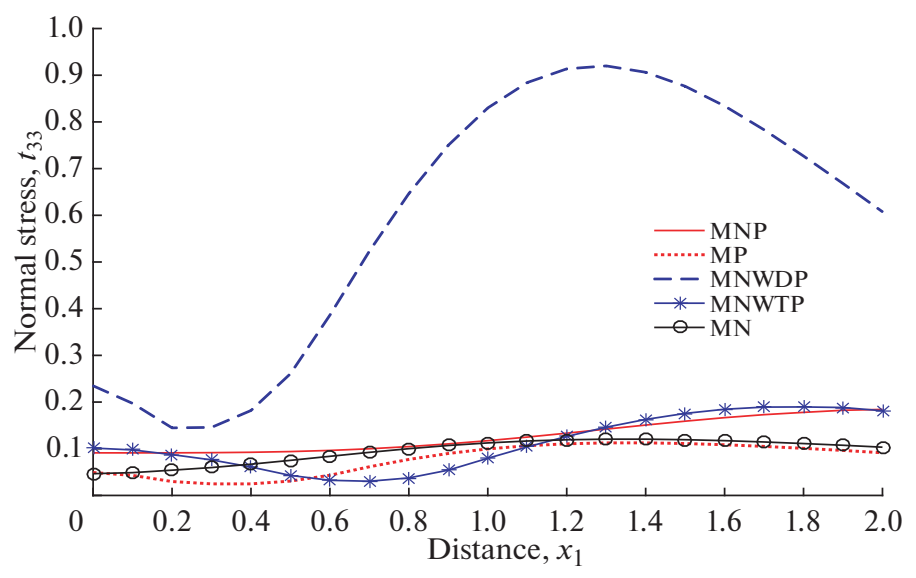

Fig. 1. Profile of normal stress $t_{33}$ vs. distance $x_{1}$.

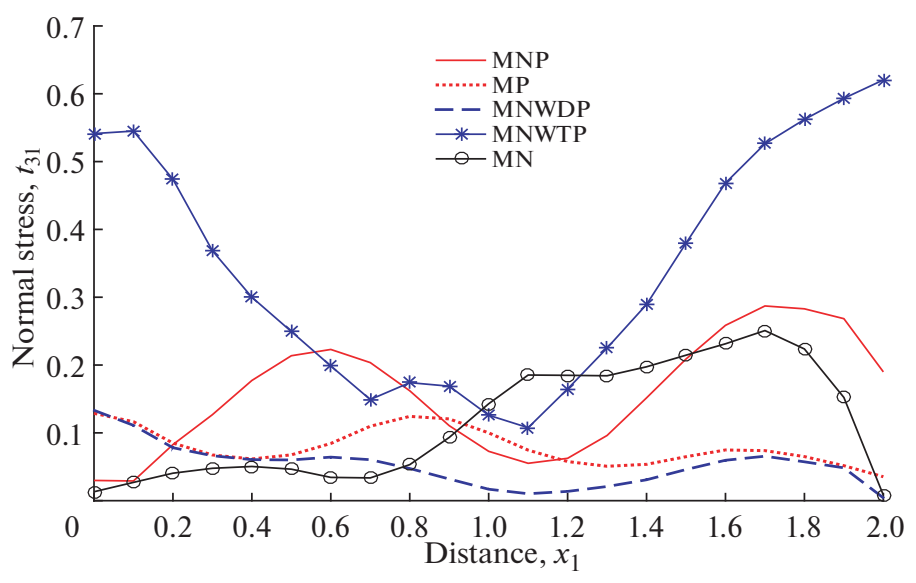

Fig. 2. Profile of tangential stress $t_{31}$ vs. distance $x_{1}$. 


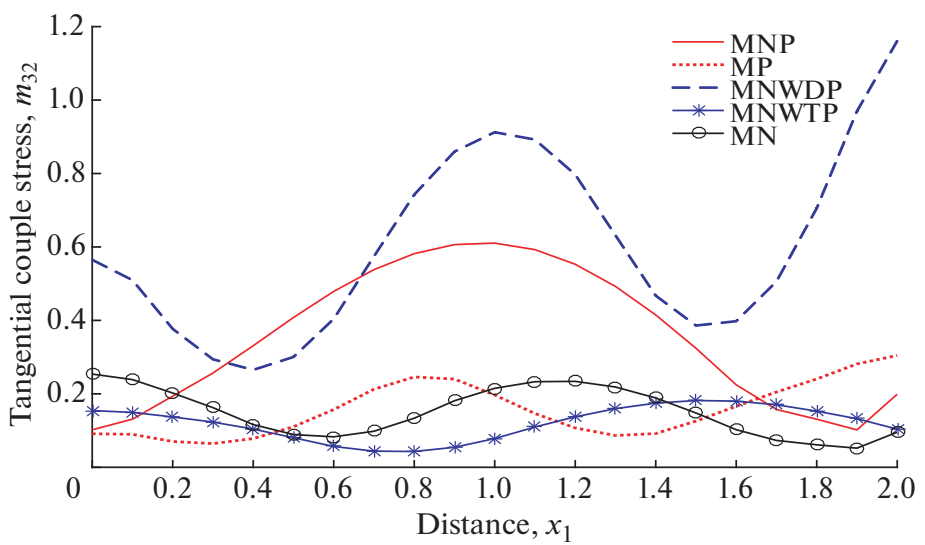

Fig. 3. Profile of tangential couple stress $m_{32}$ vs. distance $x_{1}$.

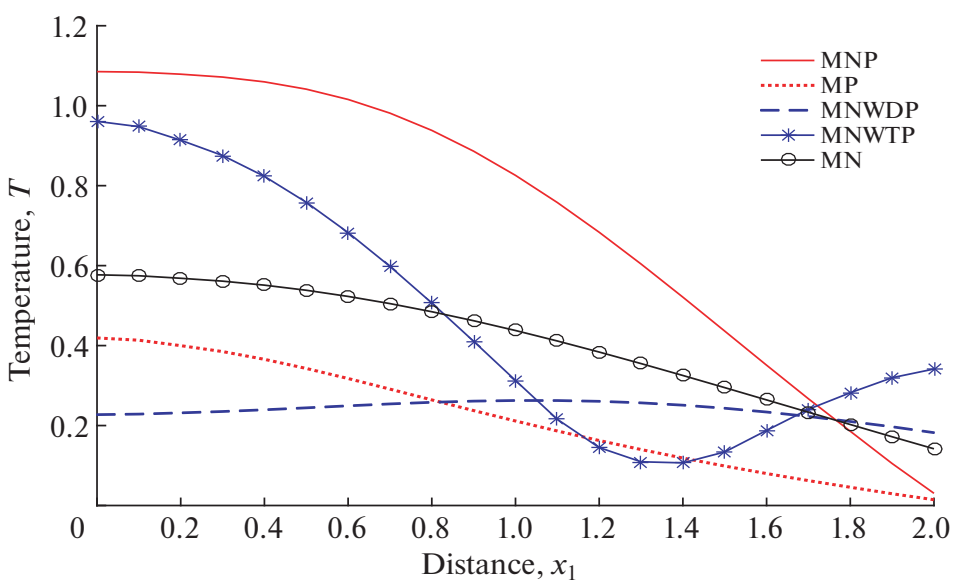

Fig. 4. Profile of temperature $T$ vs. distance $x_{1}$.

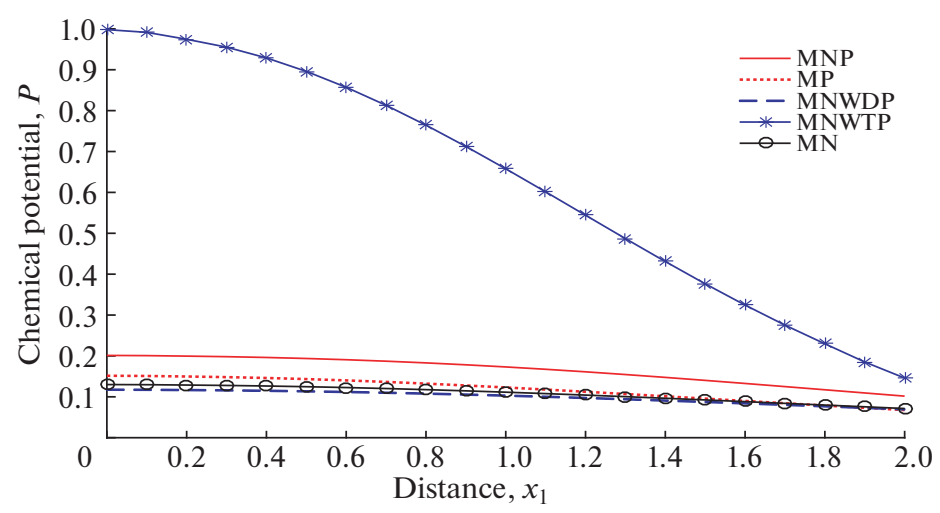

Fig. 5. Profile of chemical potential $P$ vs. distance $x_{1}$. 


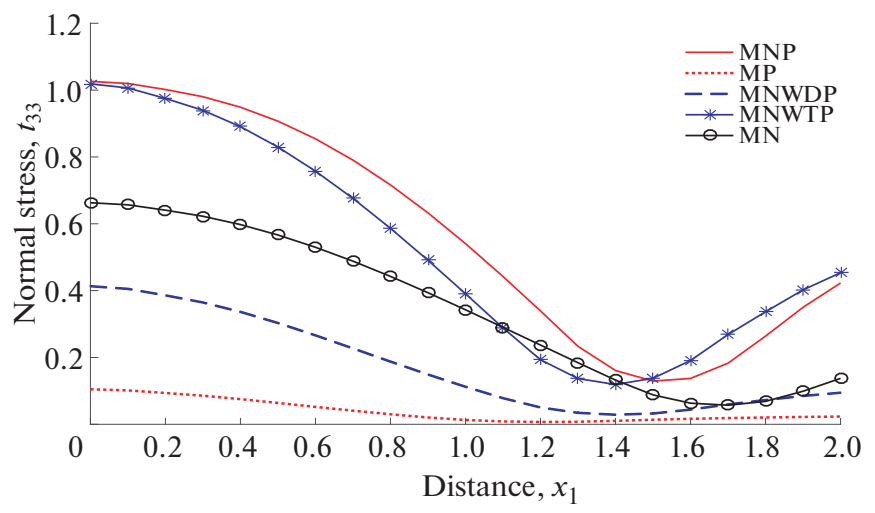

Fig. 6. Profile of normal stress $t_{33}$ vs. distance $x_{1}$.

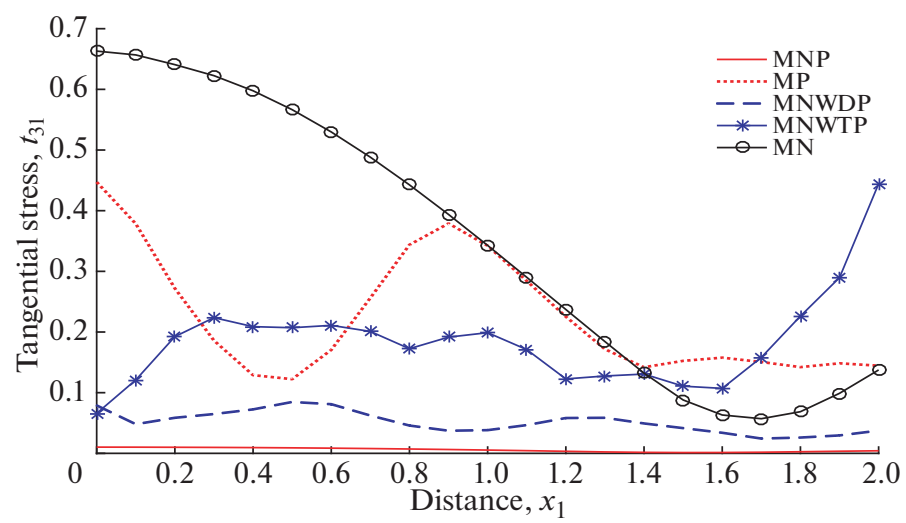

Fig. 7. Profile of tangential stress $t_{31}$ vs. distance $x_{1}$.

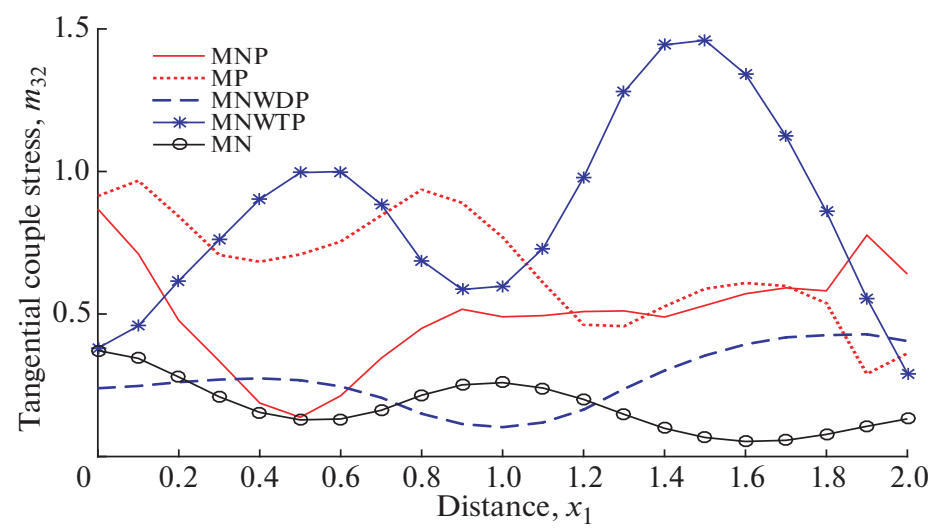

Fig. 8. Profile of tangential couple stress $m_{32}$ vs. distance $x_{1}$. 


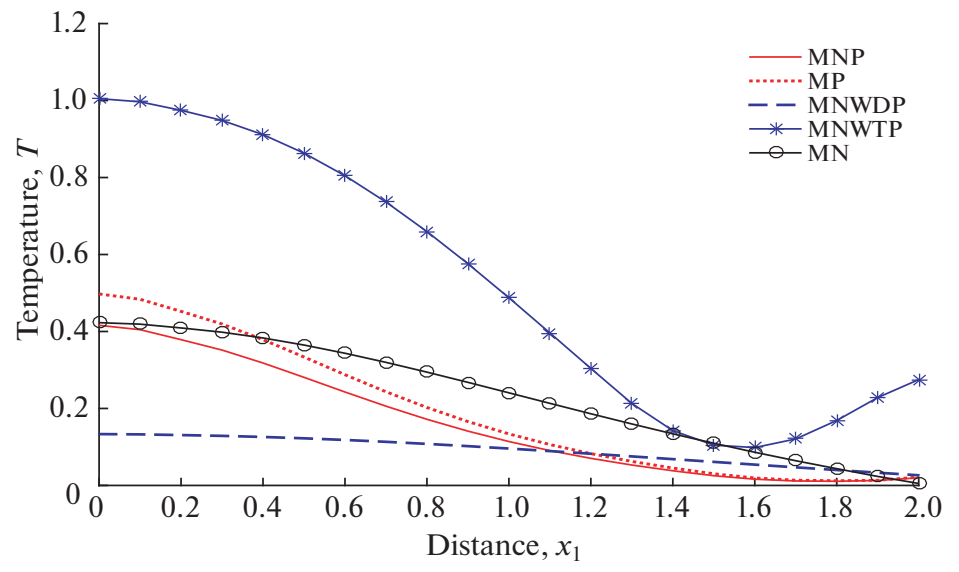

Fig. 9. Profile of temperature $T$ vs. distance $x_{1}$.

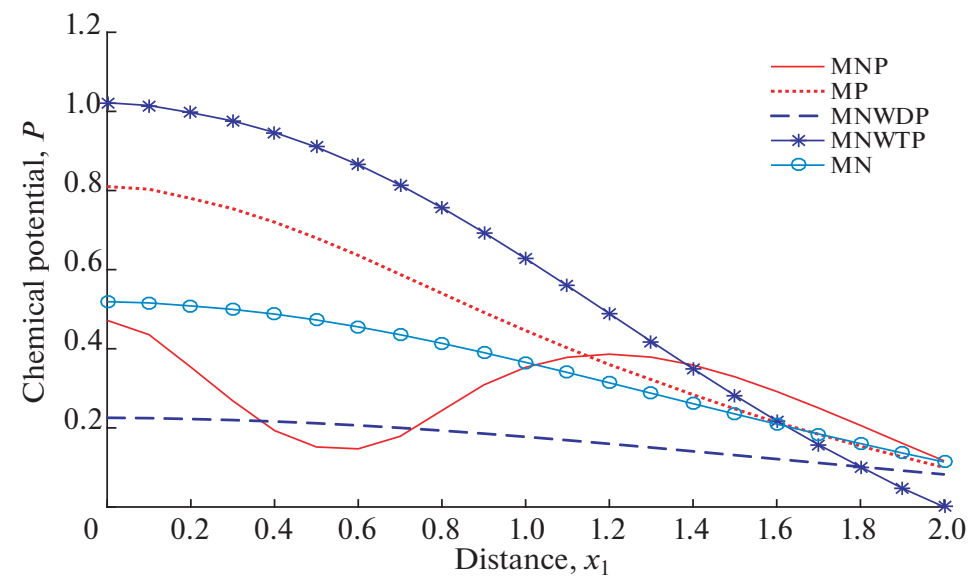

Fig. 10. Profile of chemical potential $P$ vs. distance $x_{1}$.

The original article can be found online at https://doi.org/10.3103/S0025654421040117 